\title{
Análise do estimulante sexual da life natural
}

\author{
Dr. Fabiano de Abreu Agrela Rodrigues ${ }^{1}$ \\ deabreu.fabiano@gmail.com \\ CPAH - Centro de Pesquisas e Análises Heráclito - Brasil \\ Aveiro, Castelo de Paiva - PORTUGAL
}

\section{RESUMO}

O desejo sexual se caracteriza como um impulso com o qual o sistema neurológico recebe a partir do estímulo. O sistema nervoso recebe tais estímulos, que irão resultar em uma série de substâncias químicas (libido) fazendo com que o indivíduo tenha vontade de realizar o ato. O presente estudo é uma revisão de literatura. É possível afirmar a eficácia dos estimulantes para ambos os sexos, pois os mesmos contém substâncias que possuem comprovação científica, que são eficientes para o desenvolvimento do desejo sexual.

Palavras-chave: desejo sexual; estimulante sexual; libido; extratos naturais

\footnotetext{
${ }^{1} \mathrm{PhD}$, neurocientista, neuropsicólogo, biólogo, historiador, mestre em psicanálise, pós graduação em antropologia, jornalista, especialização em inteligência artificial e em nutrição clínica.
} 


\title{
Life Natural's sexual stimulant review
}

\begin{abstract}
Sexual desire is characterized as an impulse with which the neurological system receives from a stimulation. The nervous system receives such stimuli, which results in a series of compound substances (libido) making the individual want to perform or act. The present study is a literature review. It is possible to affirm the effectiveness of stimulants for both sexes, as they contain substances that have scientific evidence, which are efficient for the development of sexual desire.
\end{abstract}

Keywords: sexual desire; sexual stimulant; libido; natural extracts

Artículo recibido: 02 enero 2022 Aceptado para publicación: 28 enero 2022 Correspondencia: deabreu.fabiano@ gmail.com Conflictos de Interés: Ninguna que declarar 


\section{INTRODUÇÃO}

Segundo a Organização Mundial de Saúde (OMS), a saúde sexual é "um estado físico, mental, um bem-estar social em relação à sexualidade, exigindo uma abordagem positiva e respeitosa com a sexualidade, com as relações sexuais, bem como com a possibilidade de se ter prazer e experiências sexuais seguras." (CHANDRA-MOULI, 2013) E em 1998, também declararam que a satisfação sexual deve ser considerada como uma qualidade de vida aos indivíduos. (GONSALVES, 2020)

As ações do sistema nervoso durante o desejo e a prática sexual são complexos e produzidos por meio de mecanismos biológicos e culturais. Este último é caracterizado como comportamento sexual que pode ocorrer devido a influências: emocionais, sociais, sensoriais e racionais. (RUNEMARK, 2018)

\subsection{Mecanismo do desejo sexual}

Fisiologicamente está relacionado com as vias dopaminérgicas centrais que estão ligadas aos mecanismos de recompensa. (BARNES, 2018) O desejo sexual se caracteriza como um impulso com o qual o sistema neurológico recebe a partir de um estímulo, que resultará em uma série de substâncias químicas (libido) fazendo com que o indivíduo tenha vontade de realizar o ato. Algumas influências emocionais podem mudar as percepções sobre o desejo sexual, apresentando-se, de diversas maneiras entre homens e mulheres. (BASSETT, 2020)

No homem após este estímulo, o cérebro encaminha respostas por meio da medula espinhal e conduz até as fibras autonômicas periféricas simpáticas e parassimpáticas para os tecidos vasculares na genitália com o intuito de promover a irrigação local. No estágio final temos o orgasmo juntamente da ejaculação. As fibras serotoninérgicas, que estão presentes na coluna espinhal e atuam juntamente as fibras descendentes noradrenérgicas que atuam na ejaculação e no orgasmo. (RATHORE, 2019)

A excitação na mulher, modifica a vagina tornando-a mais alongada, alargada e lubrificada em decorrência ao aumento da vascularização local e aumento da libido pelas células do epitélio da vagina e pelas glândulas da área. (RUNEMARK, 2018)

Outras mudanças também ocorrem como: aumento do volume uterino e sua elevação na pelve, contração de fibras musculares, os seios demonstram um pequeno aumento. E há um aumento da frequência cardíaca e respiratória. (RUNEMARK, 2018)

As demais áreas que fazem parte do aparelho genital feminino como: clitóris, grandes e 
pequenos lábios, útero e vagina, também apresentam alterações como por exemplo miotonia, avermelhanto e aumento do volume dos grandes e pequenos lábios. (BARNES, 2018)

No sistema nervoso central (SNC) estão presentes neurotransmissores importantes, que serão ativados um após o outro. Ocorre também quando o indivíduo possuí uma lembrança sexual ou estímulo, fazendo com que esses neurotransmissores e alguns hormônios sejam ativados, são eles dopamina, serotonina, noradrenalina, acetilcolina, ácido gammaminobutírico (GABA), ocitocina, arginina-vasopressina, angiotensina II, liberação do hormônio do crescimento (GRH), substância P, neuropeptídio Y, colecistocinina 8, entre outros. Tais neurotransmissores são coordenados pelo hipotálamo, sistema límbico e córtex cerebral. (RUNEMARK, 2018)

Os níveis do hormônio ocitocina após um minuto do orgasmo são significativamente mais altos. Seus níveis se elevam durante o ato, atingindo o pico um pouco antes do orgasmo demonstrando sua importância na resposta ao prazer. (RUNEMARK, 2018)

Os neurotransmissores norepinefrina e noradrenalina, atuam de modo central e periférico. Apresentam níveis elevados durante o ato sexual, este aumento no tono central resulta em maior atividade sexual, em ambos o sexos. (RUNEMARK, 2018). O neuropeptídio óxido nítrico, é um dos principais responsáveis pela ereção masculina e teria ação sobre a vasodilatação e aumento da região clitoriana. (BARNES, 2018) Outra substância importante é o peptídeo intestinal visoativo (VIP), produzido no intestino, pâncreas e núcleos supraquiasmáticos do hipotálamo. Atua na secreção de água no suco pancreático e biliar. No intestino atua na secreção de água e eletrólitos, na contração dos músculos entéricos lisos, dilata os vasos sanguíneos e estimulando o pâncreas. Durante o ato sexual provoca a lubrificação vaginal e atuando no dobrando de seu volume. (BARNES, 2018)

\subsection{Falta de desejo sexual em ambos os sexos}

Algumas patologias podem contribuir para que ocorra a falta do desejo sexual e isso como ocorrer em ambos os sexos como por exemplo: alcoolismo, uso de drogas, diabetes, problemas cardíacos, neurológicas, desequilíbrio hormonal e alguns medicamentos. (RATHORE, 2019)

Alguns distúrbios psicológicos como: ansiedade, depressão, estresse, uso contínuo de medicamentos, doenças agudas, problemas no relacionamento, podem influenciar na falta 
de libido. Nas mulheres a falta de libido também pode acabar dificultando o contato sexual e causando dor durante o sexo. (GIATTI, 2018)

Problemas hormonais como baixos níveis de testosterona, anticoncepcionais, estresse, má alimentação, idade avançada ou sedentarismo podem provocar a falta do desejo sexual. (GIATTI, 2018)

O hormônio testosterona é um dos principais hormônios sexuais que atuam no desejo sexual. Alguns estudos demonstram que mulheres na pré-menopausa demonstram que ocorre uma diminuição nos níveis de testosterona inibindo assim o desejo sexual. (GIATTI, 2018)

O neurotransmissor serotonina, quando apresentado em baixos níveis demonstra alterações na libido em ambos os sexos. Podendo afetar a excitação durante o ato sexual, dificultando o orgasmo e pode levar a ejaculação precoce. (CAROSA, 2020)

A dopamina, que é outro neurotransmissor também está relacionada ao libido, quando apresentado em níveis altos, aumenta a sensação de prazer. Nos homens quando seus níveis estão baixos, podem favorecer a ejaculação precoce. (CAROSA, 2020)

Quando a acetilcolina é liberada resulta na atenção no momento e também é responsável pela criatividade e por nos possibilitar a guardar alguma memória especial. Além disso, durante o estímulo ao desejo sexual é liberada nas terminações nervosas periféricas, contribuindo à ereção e libido. Apesar de não ser tão importante quanto a dopamina na função sexual, baixos níveis podem acabar afetando o a quantidade de sêmen. (CAROSA, 2020)

Alimentos que possuem alto teor de gordura, podem atuar no favorecimento do acúmulo de gordura nas artérias, o que pode dificultar o aumento da irrigação sanguínea para as regiões dos órgãos sexuais. (FERNANDEZ-CRESPO, 2021)

\subsection{Ativos estimuladores sexuais}

A maca peruana, nome científico Lepidium meyenii, podendo ser conhecida em algumas regiões como Ginseng-dos-Andes ou Viagra-dos-Incas, é considerado um alimento rico em fibras e gorduras essenciais. (CEDANO-CASTRO, 2020)

Sendo um tubérculo da família do agrião, nabo e repolho, é popularmente conhecido em todo o mundo por influenciar no aumento da libido e fertilidade, pois possuí propriedades que aumentam a quantidade de sêmen. (CEDANO-CASTRO, 2020)

Nas mulheres, age diretamente no hipotálamo e na suprarrenal garantindo o aumento da 
libido. Alguns estudos também relataram diminuição dos sintomas de menopausa devido ao uso da maca peruana. (CEDANO-CASTRO, 2020)

Figura 1 - Maca peruana

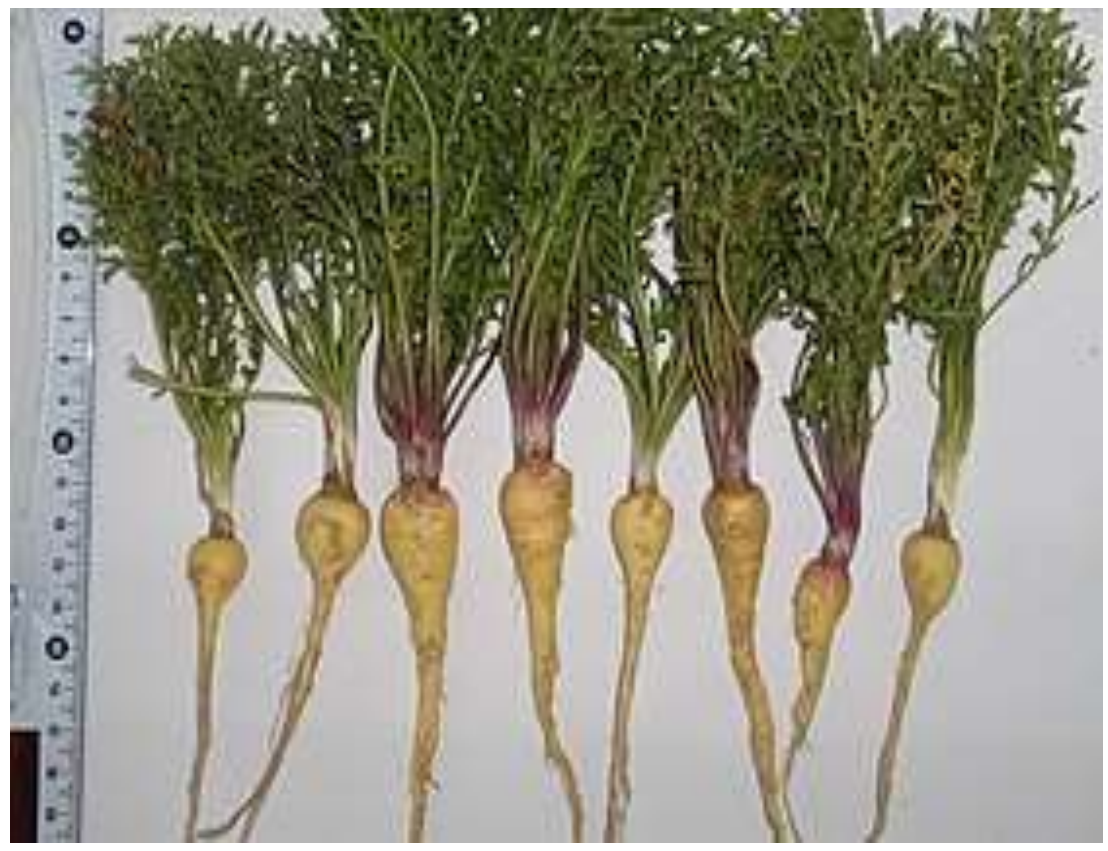

Fonte: Wikipédia

Outro extrato muito usado é a soja, também conhecida como feijão-soja e feijão-chinês, faz parte da família fabaceae, assim como o feijão, a lentilha e a ervilha. Usada na alimentação como óleo de soja, tofu, molho de soja, leite de soja, proteína de soja, soja em grão, etc. Rico em proteínas, potássio, cálcio, magnésio, fósforo, cobre, zinco, algumas vitaminas do complexo B (riboflavina e a niacina) e vitamina C. (RIZZO, 2018) Também conhecida como fitoestrógeno pois atua na prevenção de doenças crônicodegenerativas como por exemplo câncer de mama, de cólon de útero e de próstata. (RIZZO, 2018)

Possuí uma estrutura química similar ao estrógeno, sendo utilizado para combater os efeitos da menopausa e tensão pré-menstrual. E devido ao fato de ser rica em aminoácidos como o triptofano, que é um forte percursor do hormônio serotonina que quando ocorre um aumento nos níveis de concentrações no organismo, há um aumento no desejo sexual. (RIZZO, 2018) 
Figura 2 - Soja

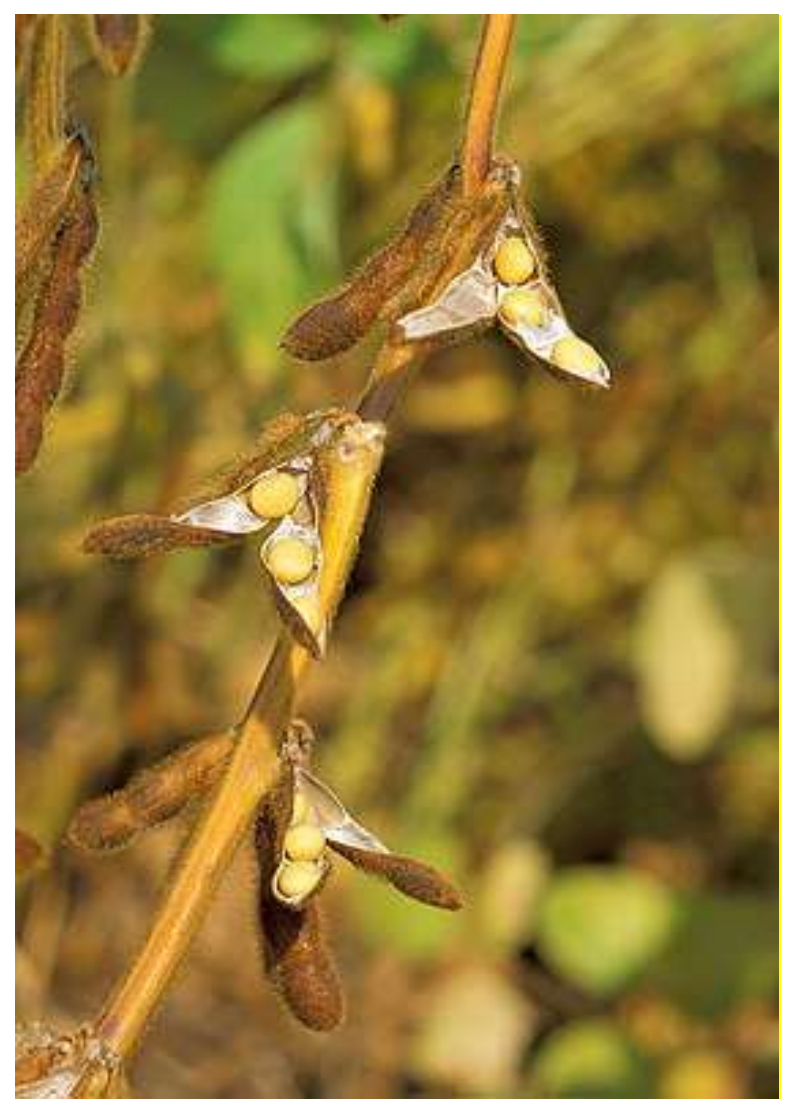

Fonte: Wikipédia

Arginina (ácido 2-amino-5-guanidino-pentanoico) classificada como um aminoácido polar e básico. Atua como carreador de nitrogênio em animais e humanos e na síntese de moléculas como agmatina, creatina, ornitina, óxido nítrico, poliaminas, prolina, dentre outras. (ALBAUGH, 2017)

Devido ao seu estimulo da vasodilatação melhora a irrigação sanguínea da região erógena da vagina, fazendo com que melhore o desejo sexual e prolongue o ato sexual. (ALBAUGH, 2017)

Figura 3 - Representação molecular da arginina<smiles>N=C(N)NCCC[C@H](N)C(=O)O</smiles>

Fonte: Wikipédia 
Zinco é um um elemento químico que possuí massa atómica de 65,4, descoberto em 1746 pelo alemão Andreas Sigismund Marggraf. A maior parte do seu uso é como metal de sacrifício. Mas também é muito usado em protetores solares como óxido, por possuir ação de barreira na radiação solar. (LOPES-RAMOS, 2020)

É um elemento essencial para a vida, atua no metabolismo das proteínas e ácido nucleico, estimulando a atividade de mais de 100 enzimas, no fortalecimento do sistema imunológico. (LOPES-RAMOS, 2020)

Existem vários estudos que avaliaram e a relação entre uma dieta rica em zinco e a sua influência no aumento da testosterona. Em um destes estudos observou-se que após a uma dieta rica em alimentos com zinco, em indivíduos que possuíam níveis baixos de testosterona, aumentaram significativamente em 6 semanas, influenciando assim no aumento do desejo sexual. (LOPES-RAMOS, 2020)

Figura 4 - Zinco

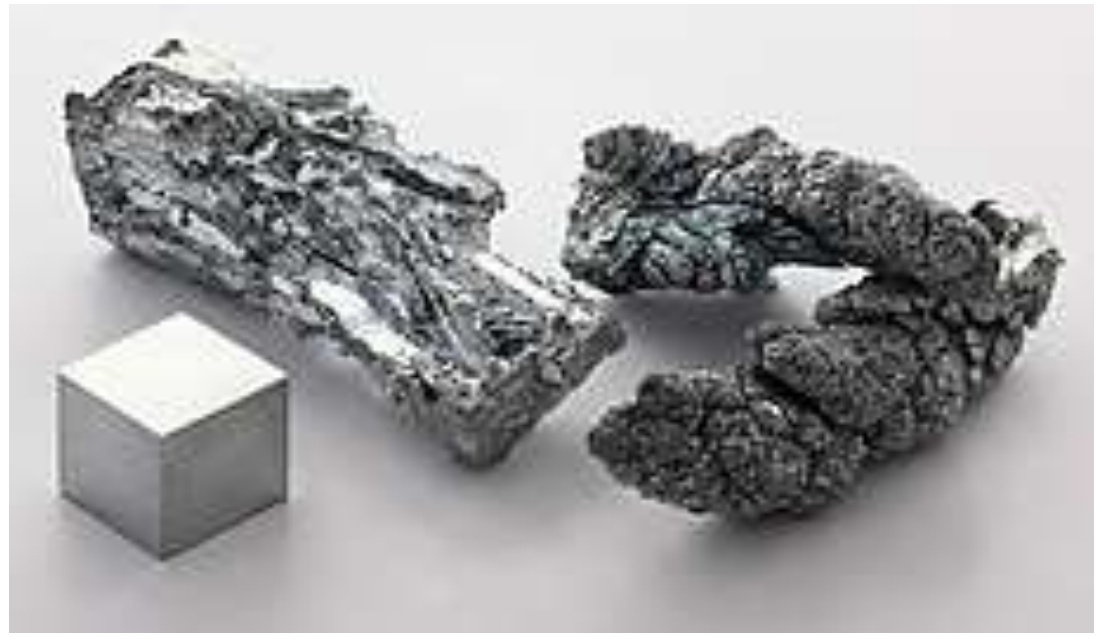

Fonte: Wikipédia

\section{4 - Life Natural feminino}

O Desejo Life é um estimulante sexual feminino, da empresa Life Natural, que utiliza componentes naturais que irão estimular o desejo sexual em mulheres.

Atua aumentando a circulação sanguínea em todo o organismo, principalmente região genital, que consequentemente irá melhorar a libido. Além disso atua em outros benefícios: alivia os sintomas da TPM, menopausa, alterações de humor, problemas de sono e irritabilidade dentre outros benefícios.

Para obter um bom resultado com o estimulante é recomendado pelo fabricante a ingestão de 1 cápsula ao dia. A seguir a bula do estimulante com todas as informações 
passadas pelo fabricante:

Contém 01 frasco com 30 capsulas.

\begin{tabular}{|l|c|c|}
\hline \multicolumn{1}{|c|}{ TABELA NUTRICIONAL } & QTD. /DOSE & $\%$ VD* \\
\hline VALOR ENERGÉTICO & $*$ & $*$ \\
\hline PROTEINAS & $*$ & $*$ \\
\hline GORDURAS TOTAIS & $*$ & $*$ \\
\hline GORDURAS SATURADAS & $*$ & $*$ \\
\hline GORDURAS TRANS & $27,5 \mathrm{mg}$ & $28 \%$ \\
\hline VITAMINA C & $10 \mathrm{mg}$ & $67 \%$ \\
\hline VITAMINA E & $34 \mathrm{mcg}$ & $57 \%$ \\
\hline SELÊNIO VITAMINA A & $3,5 \mathrm{mg}$ & $32 \%$ \\
\hline ZINCO & $*$ & $*$ \\
\hline
\end{tabular}

* Não contém quantidades significativas de Valor Energético, Carboidratos, Proteinas,

Gorduras Totais, Gorduras Saturadas, Gorduras Trans, Fibra Alimentar e Sódio.

\subsection{Life Natural masculino}

O + Vigor é um estimulante sexual masculino, da empresa Life Natural, que utiliza componentes que irão estimular o desejo sexual em homens. Atua na melhora da vasodilatação que irá estimular o organismo na obtenção e manutenção de ereções. Possuí outros benefícios como: auxilia no aumento da energia e vitalidade sexual, aumento da vasodilatação, quantidade de óxido nítrico, aumentando a oxigenação nas cavidades peniana, previne a disfunção erétil por fortalecer a musculatura peniana, melhora o vigor na atividade sexual, ajuda na formação de hormônios importantes para o bom funcionamento do organismo e melhora na circulação sanguínea e saúde cardiovascular, dentre outros benefícios.

Para obter um bom resultado com o estimulante é recomendado pelo fabricante a ingestão de 2 cápsulas por dia e indicado para maiores de 19 anos. Contem gelatina e corante, o que faz este produto ser contra-indicado para alérgicos a tais substâncias. 
A seguir a bula do estimulante com todas as informações passadas pelo fabricante:

\begin{tabular}{|l|c|c|}
\hline \multicolumn{1}{|c|}{ TABELA NUTRICIONAL } & QTD. /DOSE & \% VD* \\
\hline VALOR ENERGÉTICO & $8 \mathrm{kcal}$ & $0 \%$ \\
\hline PROTEINAS & $0,4 \mathrm{~g}$ & $1 \%$ \\
\hline GORDURAS TOTAIS & $0,7 \mathrm{~g}$ & $2 \%$ \\
\hline ARGININA & $100 \mathrm{mg}$ & $*$ \\
\hline COENZIMA Q10 & $10 \mathrm{mg}$ & $*$ \\
\hline VITAMINA A & $100 \mathrm{mcg}$ & $13 \%$ \\
\hline VITAMINA E & $10 \mathrm{mg}$ & $67 \%$ \\
\hline VITAMINA B3 & $16 \mathrm{mg}$ & $107 \%$ \\
\hline VITAMINA C & $45 \mathrm{mcg}$ & $45 \%$ \\
\hline ZINCO & $14,8 \mathrm{mg}$ & $135 \%$ \\
\hline SELÊNIO & $160 \mathrm{mcg}$ & $267 \%$ \\
\hline
\end{tabular}

*Não contém quantidades significativas de Carboidratos, Proteinas, Gorduras Saturadas, Gorduras Trans, Fibra Alimentar e Sódio.

\section{METODOLOGIA}

O presente estudo é uma revisão de literatura realizada por meio das seguintes bases de dados: PubMed, CPAH, Scielo e Google Acadêmico. Bem como a bula do estimulante feminino: Desejo Life e do estimulante masculino: + Vigor, através das informações passando pelo fabricante do mesmo: Life Natural.

\section{CONSIDERAÇÕES FINAIS}

Por meio da análise da composição de ambos os produtos, usando como referência e dos dados enviados pela empresa Life Natural.

Sendo assim, é possível afirmar a eficácia dos estimulantes para ambos os sexos, pois os mesmos contém substâncias que possuem comprovação científica por meio da publicação na revista científica e no Centro de Pesquisas e Análises Heráclito - CPAH Scientific Journal of Health confirmando que são eficientes para o desenvolvimento do desejo sexual.

Além do produtos serem autorizados e aprovados pela pela Agência Nacional de Vigilância Sanitária para comercialização. 


\section{REFERÊNCIAS}

AlBAugh, V. L., Pinzon-Guzman, C., Barbul, A. Arginine-Dual roles as an onconutrient and immunonutrient. Journal of surgical oncology, v. 115, n.3, págs. 273-280, 2017 https://doi.org/10.1002/jso.24490

BARNES, J. N., \& Fu, Q. Sex-Specific Ventricular and Vascular Adaptations to Exercise. Advances in experimental medicine and biology, v. 1065, págs. 329-346, 2018 https://doi.org/10.1007/978-3-319-77932-4_21

BASSETT, A. J., Ahlmen, A., Rosendorf, J. M., Romeo, A. A., Erickson, B. J., Bishop, M. E. (2020). The Biology of Sex and Sport. JBJS reviews, v. 8, n. 3, e0140, 2020 https://doi.org/10.2106/JBJS.RVW.19.00140

CAROSA, E., Sansone, A., Jannini, E. A. MANAGEMENT OF ENDOCRINE DISEASE: Female sexual dysfunction for the endocrinologist. European journal of endocrinology, n. 182, v. 6, p.101, 2020 https://doi.org/10.1530/EJE-19-0903

CEDANO-CASTRO, J. I., Jiménez, R., Huamán, A., Fuerst-Waltl, B., Wurzinger, M., Gutiérrez, G. Estimation of genetic parameters for four Peruvian guinea pig lines. Tropical animal health and production, v. 53, n. 1, 2020 https://doi.org/10.1007/s11250-020-02473-6

CHANDRA-MOULI, V., Bloem, P., Ferguson, J. The World Health Organization's work on adolescent sexual and reproductive health. Bundesgesundheitsblatt, Gesundheitsforschung, Gesundheitsschutz, v. 56, n.2, págs. 256-261, 2013 https://doi.org/10.1007/s00103-012-1606-0

GIATTI, S., Diviccaro, S., Panzica, G., \& Melcangi, R. C. Post-finasteride syndrome and post-SSRI sexual dysfunction: two sides of the same coin?. Endocrine, v. 61, n.2, pags. 180-193, 2018 https://doi.org/10.1007/s12020-018-1593-5

FERNANDEZ-CRESPO, R. E., Cordon-Galiano, B. H. Sexual Dysfunction Among Men Who Have Sex with Men: a Review Article. Current urology reports, v. 22, n.2, pág. 9, 2021 https://doi.org/10.1007/s11934-020-01030-w

GONSALVES, L., Cottler-Casanova, S., VanTreeck, K., Say, L. Results of a World Health Organization Scoping of Sexual Dysfunction-Related Guidelines: What Exists and What Is Needed. The journal of sexual medicine, v.17, n. 12, págs. 2518-2521, 2020 https://doi.org/10.1016/j.jsxm.2020.08.022

LOPES-RAMOS, C. M., Chen, C. Y., Kuijjer, M. L., Paulson, J. N., Sonawane, A. R., 
Fagny, M., Platig, J., Glass, K., Quackenbush, J., DeMeo, D. L. Sex Differences in Gene Expression and Regulatory Networks across 29 Human Tissues. Cell reports, v. 31, n. 12, e107795, 2020 https://doi.org/10.1016/j.celrep.2020.107795

RATHORE, C., Henning, O. J., Luef, G., Radhakrishnan, K. Sexual dysfunction in people with epilepsy. Epilepsy \& behavior E\&B, n. 100, v. 106495, 2019 https://doi.org/10.1016/j.yebeh.2019.106495

RIZZO, G., Baroni, L. (2018). Soy, Soy Foods and Their Role in Vegetarian Diets. Nutrients, v.10, n.1, 2018. https://doi.org/10.3390/nu10010043

RUNEMARK, A., Eroukhmanoff, F., Nava-Bolaños, A., Hermansen, J. S., Meier, J. I. Hybridization, sex-specific genomic architecture and local adaptation. Philosophical transactions of the Royal Society of London. Series B, Biological sciences, $\quad$ v. $373, \quad$ n. $1757, \quad$ e. $20170419, \quad 2018$ https://doi.org/10.1098/rstb.2017.0419 